\title{
The onset effect in word naming
}

\author{
Niels O. Schiller ${ }^{\mathrm{a}, \mathrm{b}, *}$ \\ ${ }^{a}$ Faculty of Psychology, Department of Cognitive Neuroscience, Universiteit Maastricht, P.O. Box 616, \\ NL-6200 MD Maastricht, The Netherlands \\ b Max Planck Institute for Psycholinguistics, P.O. Box 310, NL-6500 AH Nijmegen, The Netherlands
}

Received 10 October 2003; revision received 27 February 2004

\begin{abstract}
This study investigates whether or not masked form priming effects in the naming task depend on the number of shared segments between prime and target. Dutch participants named bisyllabic words, which were preceded by visual masked primes. When primes shared the initial segment(s) with the target, naming latencies were shorter than in a control condition (string of percent signs). Onset complexity (singleton vs. complex word onset) did not modulate this priming effect in Dutch. Furthermore, significant priming due to shared final segments was only found when the prime did not contain a mismatching onset, suggesting an interfering role of initial non-target segments. It is concluded that (a) degree of overlap (segmental match vs. mismatch), and (b) position of overlap (initial vs. final) influence the magnitude of the form priming effect in the naming task. A modification of the segmental overlap hypothesis (Schiller, 1998 ) is proposed to account for the data.
\end{abstract}

(C) 2004 Elsevier Inc. All rights reserved.

Keywords: Word naming; Onset effect; Segmental overlap; Position of overlap; Masked priming; Phonological encoding

Reading words aloud consists of at least two major components: recognition of the visual string of letters (visual word recognition) and phonological encoding of the target word. This study focuses on the second component: How are visually presented words phonologically encoded for naming? More specifically, the present series of experiments will test how much masked form priming depends on overlap in segments between prime and target, the main question being whether or not the number of shared segments is critical in the naming task. As a corollary of this general theme, I will investigate whether or not the position (initial vs. final) of the overlapping segments is important.

Most computational models of visual word recognition (Plaut, McClelland, Seidenberg, \& Patterson, 1996; Zorzi, Houghton, \& Butterworth, 1998) assume that the

\footnotetext{
${ }^{*}$ Fax: +31-43-3884125/31-24-3521213.

E-mail addresses: n.schiller@psychology.unimaas.nl, niels. schiller@mpi.nl (N.O. Schiller).
}

phonology of a word is computed in parallel from its orthography. However, the dual-route cascaded (DRC) model developed by Coltheart and colleagues (Coltheart, Curtis, Atkins, \& Haller, 1993; Coltheart, Rastle, Perry, Langdon, \& Ziegler, 2001) makes the assumption of a serial component involved in translating a string of letters into a sound form. This assumption is supported, for instance, by the position of irregularity effect. This effect refers to the finding that the latency to name an irregular word is longer when the exceptional spellingto-sound correspondence occurs earlier in the word than when it occurs later in the word (Coltheart \& Rastle, 1994; Cortese, 1998; Job \& Peressotti, 2001; Rastle \& Coltheart, 1999). Similarly, Coltheart, Woollams, Kinoshita, and Perry (1999) reported a position-sensitive Stroop effect. Color naming responses are faster when the printed word shares a phoneme with the color name to be produced than when it does not. This effect is larger when stimulus and response share the first phoneme (e.g., rat-red) than when they share the last phoneme (e.g., pod-red). 
Another position-dependent effect supporting the seriality assumption is the masked onset priming effect (MOPE). In a masked priming paradigm, Forster and Davis (1991) found that one determinant of word naming latencies appears to be a shared initial segment. For instance, the prime-target pair pole-PAIR yielded shorter naming latencies than take-PAIR. However, Forster and Davis (1991) concluded that this masked onset priming effect is a special effect unrelated to genuine form priming. It only occurs for words whose pronunciation is influenced by the non-lexical naming system (i.e. grapheme-to-phoneme conversion, GPC) such as non-words, low-frequency words, and words from high-density neighborhoods. Words, whose pronunciation is lexically controlled, such as high-frequency words, low-density words, and irregular words, do not show a masked onset priming effect (see Kinoshita, 2003 for a review). This led Forster and Davis (1991) to account for the onset effect in terms of a response competition hypothesis. Participants engaged in a naming task may begin to assemble at least the pronunciation of the initial segment upon presentation of the masked prime which leads to a competing tendency to pronounce the prime as well as the target. When prime and target have the same onset, the first segment of the target is already activated for pronunciation by the prime and the target can be named faster suggesting that phonological and/or phonetic-articulatory activation is involved. In contrast, when they have different onsets there is Stroop-like response competition between the prime's and the target's initial segment. Such a competition has to be resolved, leading to slower naming responses than in the onsetmatching case. This, however, holds only for words whose pronunciation is strongly influenced by the nonlexical route, i.e., grapheme-to-phoneme conversion must be involved for this account to work.

More recently, Kinoshita (2000) replicated the masked onset priming effect. In her first experiment, she found an effect for begin-related ( $s u f-\boldsymbol{S I B}$ ) but not for end-related primes $(m u \boldsymbol{b}-S I \boldsymbol{B})$ in a non-word naming task. In her second experiment, Kinoshita (2000) showed that it is not the initial consonant that was responsible for the MOPE, but the syllable onset as a unit since a MOPE was obtained only when the target had a singleton onset (penny$\boldsymbol{P} A S T E$ ) but not when it began with a consonant cluster (bingo-BLISS). This outcome supports and qualifies the MOPE (see also Kinoshita \& Woollams, 2002).

In the following, I will refer to the term form priming whenever priming is due to some sort of orthographic or phonological form similarity between a prime and a target. In that sense, the masked onset priming effect is also a form-priming effect because prime and target have the same onset, although Forster and Davis (1991) suggested that the MOPE is unrelated to form priming proper. The response competition hypothesis predicts that for target words with certain lexical characteristics (low-frequency words, non-words, high-density words, etc.), which strengthen the probability of non-lexical naming (GPC), there can be low-level priming (response preparation) when the prime starts with the same onset as the target. This effect, however, is interpreted as a non-lexical effect, whereas genuine form priming is usually seen as occurring at the lexical level (Forster, 1998; Forster, Mohan, \& Hector, 2003, for a review; but see Bodner \& Masson, 1997, 2001 for a different position). When there is a masked onset priming effect, all other segmental overlap beyond the onset does not have an influence, e.g., goat-GOLD primes just as well as gord-GOLD (Forster \& Davis, 1991, Experiment 3).

Another form-priming hypothesis is the segmental overlap hypothesis $(\mathrm{SOH})$ developed by Schiller (1998), which predicts that the magnitude of a form-priming effect in naming is contingent on the amount of segmental overlap between prime and target. The onset has no special status for the segmental overlap hypothesis, whereas it is the only source of priming hypothesized by the response competition hypothesis. The segmental overlap hypothesis predicts an effect of end-relatedness, but end-related overlap in the absence of mismatching initial segments has not been tested so far. Schiller (1998) varied the prime-target overlap from only one segment (shared onset) to complete overlap (identity priming) using the word-naming task in Dutch (Experiment 5). In that experiment, a monotonic increase in priming effects from one shared segment to complete overlap was obtained, i.e. a segmental overlap effect. According to Schiller (1998, 2000; Schiller, Costa, \& Colomé, 2002), phonological encoding for production is facilitated when the (phonological) segments of the tobe-produced lexical item are pre-activated by the visual prime prior to overt production. The segmental overlap hypothesis predicts that the amount of facilitation depends on the amount of segmental overlap, whether initial or final, between prime and target-at least as long as there are no mismatching segments present. ${ }^{1}$

\footnotetext{
${ }^{1}$ One may argue that Schiller's $(1998,2000)$ results were due to a masked onset priming effect since the stimulus characteristics would have allowed for a MOPE. He used bisyllabic targets of low to moderate frequency. Schiller's targets were therefore comparable to the low-frequency bisyllabic words used in Experiment 5 of the Forster and Davis (1991) study. For those targets, the latter authors demonstrated both a masked onset priming effect (e.g., bellom-BELLOW vs. dellow-BELLOW) and a general form-priming effect in spite of onset mismatch between prime and target (e.g., dellow-BELLOW vs. nuffer$B E L L O W)$. Therefore, it might well be that the effects observed by Schiller $(1998,2000)$ were due to a MOPE. However, since a MOPE is due to response preparation and can only affect the initial segment of a word, all priming conditions should have yielded the same effect in Schiller's (1998) Experiment 5, because they all had the same onset. The results of Schiller's Experiment 5 , however, showed a segmental overlap effect.
} 


\section{Predictions of the segmental overlap hypothesis}

A strong or pure version of the segmental overlap hypothesis would predict that the magnitude of form priming in naming only depends on the number of overlapping segments between prime and target-whether or not there are mismatching segments in the prime. In the current study, the effect of mismatching segments (e.g., glory-STORY) for the segmental overlap effect is to be tested (Experiments 1 and 2). Their role for the segmental overlap hypothesis has been neglected so far, but it is important to know whether or not they have an interfering influence on naming. It might be the case, for instance, that segmental mismatch could cause response competition at the level of the output phonology (response competition hypothesis; Forster \& Davis, 1991). Alternatively, mismatching segments could cause the pre-activation of non-target segments (i.e. /g/ and ///) at an orthographic or phonological level, which would have to be suppressed before the correct segment(s) can be retrieved for naming. The potentially interfering effect of mismatching segments might account for Kinoshita's (2000) failure to obtain an effect for end-related primes (e.g., $m u \boldsymbol{b}-S I \boldsymbol{B})$. If it turns out that mismatching segments have an influence in naming, the segmental overlap hypothesis will have to be modified.

Furthermore, the $\mathrm{SOH}$ has only been tested with begin-related overlap between prime and word target (e.g., Schiller, 1998, 2000). Although the SOH would predict an effect from end-related primes, word-final form overlap and its consequences for a segmental overlap effect have not been tested systematically so far. Recently, at least two studies failed to obtain form priming from end-related primes (i.e. Kinoshita, 2000 as well as O'Seaghdha \& Marin, 2000), but both studies included mismatching initial segments. By testing end-related segmental overlap in the absence of onset mismatch it might be possible to determine the role of mismatching initial segments (see also Grainger \& Ferrand, 1996 and Montant \& Ziegler, 2001), thus estimating the individual contributions of the masked onset priming effect and the segmental overlap effect in form priming (Experiments 1 and 2).

Last but not least, Kinoshita's (2000) finding that onset complexity plays a role for the onset effect is not predicted by a pure segmental overlap hypothesis, which does not take syllable structure complexity into account. Syllable onsets, however, have been reported to play a role in meta-linguistic tasks - at least in English, e.g., in the work of Treiman and collaborators (e.g., Treiman, 1985, 1986; Treiman, Fowler, Gross, Berch, \& Weatherston, 1995; Treiman \& Zukowski, 1996). Therefore, I included targets beginning with singletons and consonant clusters in order to determine whether or not the factor onset-complexity plays a role in Dutch as well
(Experiment 3). Finally, I will discuss the consequences of the findings for the response competition hypothesis and the segmental overlap hypothesis.

\section{Experiment 1: Word naming with begin- and end-related masked primes}

The first experiment of this study is inspired by the third experiment of O'Seaghdha and Marin (2000). In Experiment 3 of their study, bisyllabic target words (e.g., $S T O R Y$ ) were preceded by masked primes that were either begin-related (e.g., storage) or end-related (e.g., glory). Begin-related primes facilitated naming significantly (compared to unrelated primes, e.g., collar), whereas end-related primes did not produce any effect (compared to unrelated primes, e.g., fracture). Interestingly, this was true not only for high-frequency target words, but also for low-frequency targets, i.e., words for which Forster and Davis (1991) did find genuine form priming in their Experiment 5 even in the absence of a matching initial segment (e.g., dellow-BELLOW vs. nuffer-BELLOW). ${ }^{2}$ While O'Seaghdha and Marin (2000) admit that it is not completely clear why there was no effect of end-relatedness in naming, they suggest that it may have to do with an onset effect: In their endrelated condition, there was always an onset mismatch between prime and target. Therefore, response competition may have blocked or canceled out the formpriming effect from the shared final segments in that condition (see Forster \& Davis, 1991). If this account were correct, a condition where prime and target do not mismatch in the onset (as they did in glory-STORY) but are still end-related (as e.g., in $\% \% \% \boldsymbol{r y}$-STORY) might produce priming (see also Grainger \& Ferrand, 1996).

One might wonder why participants would not try to pronounce " $r y$ " as the onset of the target, i.e. STORY in this latter case. However, by the time the system has processed the percent signs and isolated the linguistic content "ry," it is probably too late to influence the pronunciation of the target. Furthermore, there seems to be evidence that the visual word processing system

\footnotetext{
${ }^{2}$ The frequency of occurrence of the low-frequency words in the O'Seaghdha and Marin (2000) study was 4.3 per one million words, and in the Forster and Davis (1991) study it was 5.7 per million words. That is, the frequency characteristics of the low-frequency words were very similar in both studies. Furthermore, word length was also comparable between the fifth experiment of the Forster and Davis (1991) study (5.5 letters) and the third experiment of the O'Seaghdha and Marin (2000) study (6.2 letters). As for the average neighborhood density, the low-frequency items in the Forster and Davis (1991, Exp. 5) had very few neighbors (1.94), whereas the number of neighbors in the O'Seaghdha and Marin (2000) study was not specified for the low-frequency items.
} 
is sensitive to the position of letters within a string. For example, there is a large body of evidence from the visual word recognition literature supporting a relativeposition coding of letters (Grainger \& Whitney, 2004; Peressotti \& Grainger, 1995, 1999; Stevens \& Grainger, 2003). The connectionist dual-process model of reading by Zorzi et al. (1998) assumes that letters are represented in a positional code, where each node in the input layer of the network represents a letter and its position in the word. Letter positions are defined with respect to orthographic onsets and rimes. Support for this claim will be provided in Experiment 2.

According to the pure version of the segmental overlap hypothesis, priming effects should be visible independently of the location of the segmental overlap, unless priming effects are canceled out due to segmental mismatch between prime and target. To test this aspect of the $\mathrm{SOH}$, bisyllabic words were named on separate trials preceded by a begin-related (balans-BANAAN), an end-related (propaan-BANAAN), a first-syllable ( $b a-$ $B A N A A N$ ), a second-syllable (naan-BANAAN), and a control prime (string of percent signs) in Experiment 1. The two "syllabic" priming conditions were not present in the O'Seaghdha and Marin (2000) study. In these conditions, the segmental overlap hypothesis predicts a form-priming effect, whereas the predictions for beginand end-related conditions are less clear due to the presence of mismatching segments.

\section{Method}

\section{Participants}

Fourteen undergraduate students from the University of Nijmegen took part in Experiment 1. All were native speakers of Dutch and had normal or correctedto-normal vision. They were paid for their participation in the experiment.

\section{Procedure}

The procedure was similar to the one used in Schiller (1998). Participants were tested individually in a dimly lit, soundproof room. They were seated about $60 \mathrm{~cm}$ from a computer screen. Target words appeared as white capital letters on a black screen and remained in view until a response was given or $2000 \mathrm{~ms}$ had elapsed. Before the presentation of a target, a fixation point appeared for $500 \mathrm{~ms}$ in the middle of the screen on which participants were asked to fixate. Then a row of hash marks (\#'s) that matched the length in letters of the longest prime (10 characters) appeared for $500 \mathrm{~ms}$ as a forward mask and replaced the fixation point. Immediately afterwards, the prime was presented in lower case for $50 \mathrm{~ms}$ (57 ms in O'Seaghdha \& Marin, 2000), followed by a backward mask for $17 \mathrm{~ms}$, which was identical to the forward mask. This backward mask was not present in other studies such as O'Seaghdha and Marin
(2000), Forster and Davis (1991), and Grainger and Ferrand (1996). The target immediately replaced the backward mask. In earlier studies, I formally assessed that under these masking conditions participants are generally not able to recognize the primes (see prime visibility tests reported in Schiller, 1998, p. 489 and Schiller, 2000, p. 517). Informal interviewing of the participants at the end of the present experiments revealed that many participants noticed some sort of flickering before the target word appeared on the screen. However, nobody was able to identify prime words between the masks. The current experiments were run in the same laboratory using the same equipment and prime exposure duration as the experiments reported in the Schiller (1998) study. All stimuli were centered on the screen. Before and after the prime percent signs ("\%") were added until the prime matched the length of the masks (see examples below). This procedure was used to avoid additional flickering on the screen due to presentation of stimuli differing in length. Forster and Davis (1991), Kinoshita (2000), as well as O'Seaghdha and Marin (2000) did not use percent signs in their studies. Naming latencies (reaction times; RTs hereafter) were measured with a voice key from target onset. Trial sequencing was controlled by NESU (Nijmegen Experimental Set-Up). The presence of a prime was not mentioned to the participants. Participants were instructed to name the target as fast as possible while avoiding errors. When a response was given, the next trial started after $1000 \mathrm{~ms}$. Materials were blocked into sets of 25 items, and after each block the mean RTs were displayed on the screen. Participants were asked to write down their mean RTs. The purpose of this was to speed participants up and to exclude task-unrelated cognitive processes as much as possible.

\section{Design}

Across the experiment, each target was preceded by five primes: a begin-related (e.g., \%\%balans\%\%-BANAAN), a first-syllable (e.g., \%\%ba\%\%\%\%\%\%-BANAAN), an end-related (e.g., \%propaan\%\%-BANAAN), a secondsyllable (e.g., \%\%\% \% naan\%\%-BANAAN), and a control prime (e.g., \%\%\%\%\%\%\%\%\% -BANAAN). O'Seaghdha and Marin (2000) used different control primes (unrelated words). The total of 225 trials ( 45 words $\times 5$ priming conditions) was divided into 9 blocks of 25 trials. In each block, there was an equal number of each priming condition. Blocks were randomized individually for each participant.

\section{Materials}

Forty-five monomorphemic, bisyllabic Dutch words were chosen as targets. All words referred to concrete nouns and were of moderate to high frequency (16.9 per one million word forms according to CELEX; Baayen, Piepenbrock, \& Gulikers, 1995). The mean 
neighborhood density was 12.87. Taking an item's neighbors, i.e., all words differing in one phoneme from the item itself, and weighting these neighbors by their log-transformed CELEX frequencies defined neighborhood density. The sum of those frequencies yielded a frequency-weighted neighborhood density (Newman, Sawush, \& Luce, 1997). Begin- and end-related primes were chosen in a way as to maximize the segmental overlap with the targets. Prime-target overlap (as a proportion of the number of target segments) in beginand end-related conditions was 45 and $65 \%$, respectively. As syllabic primes, the first and the second syllable of the target were chosen. The prime-target overlap in the first- and second-syllable priming condition was on average 43 and $51 \%$, respectively. The complete list of target words and primes used in Experiment 1 can be found in Appendix A.

\section{Results}

Naming latencies shorter than $300 \mathrm{~ms}$ or longer than $1000 \mathrm{~ms}$ were counted as outliers $(0.5 \%$ of the data) and discarded from the analyses. The mean naming latencies and error rates are summarized in Table 1. An analysis of variance (ANOVA) was run with Type of Prime (word vs. syllable) and Position of Overlap (initial vs. final) as independent variables. In all experiments reported in this study, separate analyses were carried out with participants $\left(F_{1}\right)$ and items $\left(F_{2}\right)$ as random variables.

\section{Naming latencies}

The main effect of Type of Prime was significant by subjects and marginally significant by items $\left(F_{1}(1\right.$, $13)=7.92, M S_{\mathrm{e}}=23.55, p<.05 ; F_{2}(1,44)=3.29, M S_{\mathrm{e}}=$ $235.44, p=.077)$. Syllabic primes yielded slightly faster RTs than whole word primes. The main effect of Position of Overlap was also significant $\left(F_{1}(1,13)=63.18\right.$, $M S_{\mathrm{e}}=22.13, p<.01 ; F_{2}(1,44)=22.90, M S_{\mathrm{e}}=179.36, p$ $<.01)$ showing that initial overlap yielded faster RTs than final overlap. These two factors did not interact $\left(F_{1}(1,13)=1.60, M S_{\mathrm{e}}=70.46\right.$, n.s.; $F_{2}(1,44)=1.51, M S_{\mathrm{e}}$ $=194.53$, n.s.).

Pair-wise comparisons (Bonferroni adjusted $\alpha=.008)$ showed that the effect of begin-related primes
(17 ms) as well as the effect of first-syllable primes (19 ms) were highly significant relative to the control condition $\left(t_{1}(13)=6.86, S D=9.65, p<.005 ; t_{2}(44)=6.60, \quad S D=\right.$ $17.19, p<.005$ and $t_{1}(13)=8.02, S D=8.64, p<.005$; $t_{2}(44)=7.05, S D=17.62, p<.005$, respectively). Furthermore, the effect of second-syllable primes $(12 \mathrm{~ms})$ was clearly significant $\left(t_{1}(13)=5.17, S D=8.20, p<.005\right.$; $\left.t_{2}(44)=5.19, S D=14.87, p<.005\right)$, but not the effect of end-related primes $(5 \mathrm{~ms})$ relative to the control condition $\left(t_{1}(13)=2.26, S D=8.05, p=.042 ; t_{2}(44)=1.96, S D=\right.$ $16.47, p=.057)$.

The advantage of the initial vs. final overlap is further demonstrated by the differences between the begin- and the end-related condition $(12 \mathrm{~ms})$ and between the first- and the second-syllable condition $(7 \mathrm{~ms})$, which were significant $\left(t_{1}(13)=4.23, S D=11.35, p<.005\right.$; $t_{2}(44)=3.81, S D=21.32, p<.005$ and $t_{1}(13)=3.57$, $S D=7.51, p<.005 ; t_{2}(44)=2.74, S D=17.13, p=.009$, respectively).

\section{Error rates}

The overall error rate was $2.8 \%$. The experimenter did not notice "blending errors" (e.g., propaan $+B A$ $N A A N=$ "pranaan") in any of the experiments reported in this manuscript, presumably due to the non-lexical status of most of the potential blending errors (Dell \& Reich, 1981). There were no significant effects in the error analysis.

\section{Discussion}

Experiment 1 showed that form priming could be obtained in the word-naming task for primes with initial as well as with final overlap. However, there were some differences between whole-word primes and syllable primes. As predicted by the segmental overlap hypothesis, priming could be achieved in the absence of the onset information (second-syllable condition), replicating Grainger and Ferrand's (1996) as well as Montant and Ziegler's (2001) results. Whereas the effect yielded by the first-syllable condition could theoretically be due to a masked onset priming effect or a segmental overlap effect, the second-syllable effect must be due to a segmental overlap effect and not a MOPE, since this condition lacks onset overlap with the target. However,

Table 1

Mean naming latencies (in milliseconds) and percentage errors (in parentheses) in Experiment 1

\begin{tabular}{lccc}
\hline Condition & Example & Mean RT & Mean priming effect (Control-Condition) \\
\hline Begin-related & $(\% \%$ balans\%\%-BANAAN) & $418(3.7)$ & $17(-1.2)$ \\
First-syllable & $(\% \%$ ba\%\%\%\%\%-BANAAN) & $416(2.9)$ & $19(-0.4)$ \\
End-related & $(\%$ propaan\%\%-BANAAN) & $430(1.7)$ & $5(0.8)$ \\
Second-syllable & $(\% \% \% \%$ naan\%\%-BANAAN) & $423(2.7)$ & $12(-0.2)$ \\
Control & $(\% \% \% \% \% \% \% \%$-BANAAN) & $435(2.5)$ & \\
\hline
\end{tabular}


no priming effect was observed in the case of mismatching onset information (end-related condition), suggesting some sort of interference from mismatching initial segments (see below). In contrast, begin-related primes facilitated naming, i.e., there was no interference from final segments. Therefore, the present results are similar to the outcome of the third experiment of the O'Seaghdha and Marin (2000) study.

In the current experiment, an effect of response competition could have contributed to the pattern obtained: The end-related prime propaan may have preactivated its onset segment $/ \mathrm{p} /$, which led to response competition with the onset /b/ of the target banaan. Alternatively, mismatching initial segments (e.g., propaan-BANAAN) activating non-target segments $(/ \mathrm{p} /, / \mathrm{r} /$, $/ \mathrm{o} /$ ) at the level of phonological encoding might be responsible for the elimination of the form-priming effect in the end-related condition. This is also suggested by the second-syllable priming effect: The final segmental overlap between the second-syllable prime naan and $B A N A A N$ (i.e., /nan/) still facilitated naming compared to a control condition in this experiment, which was not the case when mismatching segments were present. In contrast to the final overlap conditions, begin-related and first-syllable conditions both facilitated naming relative to a control condition, i.e., $b a$ yielded just as much priming for $B A N A A N$ as $b a-$ lans. This finding suggests that either mismatching segmental information in the final part of the prime does not lead to interference, or a masked onset priming effect occurred in both begin-related conditions and therefore no further facilitatory or inhibitory effects occurred.

Generally, the results showed that initial mismatch (e.g., /prop/-/ba/) weakens the effect of end-related primes but it is not clear whether or not this is due to response competition between mismatching onset segments or interference from non-target segments at the level of phonological encoding. In the begin-related condition (e.g., balans-BANAAN), final segmental mismatch between prime and target does not seem to have such an interfering effect, possibly because of a masked onset priming effect and/or the fact that participants sometimes began to speak before having encoded both syllables of the target word.

Next, I consider the role of the position of segmental overlap. In Experiment 1, there was a main effect of Position of Overlap (initial primes yielded stronger facilitation than final primes). Furthermore, although the first-syllable (e.g., $b a-B A N A A N)$ as well as the secondsyllable condition (e.g., naan-BANAAN) yielded significant priming effects, the first-syllable condition was significantly stronger than the second-syllable condition even though the amount of segmental overlap favored the second-syllable condition. According to the segmental overlap hypothesis, the two syllabic conditions should have yielded approximately the same amount of priming. Why was the outcome different? One possibility is that the first syllable condition caused a masked onset priming effect: First-syllable primes (e.g., $b a$ ) may activate the same initial segment (i.e., /b/) as the target word (e.g., banaan). If participants assemble the pronunciation of the initial segment upon presentation of the prime, a first-syllable prime will activate the same segment as the target onset. In contrast, end-related primes (e.g., naan) cannot activate the same segment as the target onset but only produce a general form priming effect. Response preparation due to the masked onset priming effect possibly results in a larger priming effect in the first-syllable condition than the general form priming effect obtained in the second-syllable condition. The overall advantage of initial over final primes could also be accounted for by assuming a masked onset priming effect since segmental overlap is approximately matched in both conditions. In summary, the contributions of a segmental overlap effect and a MOPE could not be isolated in Experiment 1. In the next experiment, I will try to disentangle the two effects. In Experiment 2, so-called reversed primes will be used to shed more light on the relative contributions of both segmental overlap effect and MOPE.

\section{Experiment 2: Word naming with reversed primes}

The second experiment was set up to disentangle the relative contributions of the masked onset priming effect and the segmental overlap effect to form priming. ${ }^{3}$ According to a pure segmental overlap hypothesis, form priming is driven only by the overlap in activated segments between prime and target regardless of where the overlap occurs. Therefore, it should in principle not matter whether for the target $B A N A A N$ the related prime balans is presented in the correct order, or with both syllables reversed (i.e. lansba) since the overlap in segments is the same and hence both primes would activate the same number of matching and mismatching segments. These conditions are important to demonstrate how much priming is due to a pure segmental overlap effect, since any priming of lansba compared to a control condition must be due a segmental overlap effect.

In contrast, a pure response competition hypothesis would predict that form priming is driven exclusively by the onset. Therefore, priming would only be expected for balans, but not for lansba when $B A N A A N$ is the target. That is, the comparison of balans with lansba allows me to isolate the contribution of a masked onset priming

\footnotetext{
${ }^{3} \mathrm{I}$ am indebted to Glen Bodner for suggesting this experiment to me.
} 
effect over and above a (pure) segmental overlap effect since any advantage of balans over lansba must be due to a MOPE. Furthermore, by comparing the primes lansba and $\% \% \% b a$, I might be able to determine the influence of a mismatching onset and mismatching segments in word naming.

\section{Method}

\section{Participants}

Sixteen participants from the same pool as described for Experiment 1 took part in the experiment.

\section{Procedure}

The procedure was identical to Experiment 1.

\section{Design}

Across the experiment, each target word was preceded by four different primes: a begin-related prime (e.g., \%\%balans\%\%-BANAAN), a reversed begin-related prime (i.e., a prime consisting of the same syllables as the begin-related prime, but in reversed order, e.g., $\%$ lansba\%\%-BANAAN), a reversed first-syllable prime (i.e., a prime consisting of the first syllable, which appears at the final part of the prime, e.g., \%\%\%\%\% ba\%\%BANAAN), or a control prime (e.g., \%\%\%\%\%\%\%\%\%BANAAN). The total of 180 trials ( 45 words $\times 4$ priming conditions) was divided into six blocks. In addition, there were 10 warm-up trials including different words paired with control primes, which were presented before the first block. In each block, there was an equal number of target word types and an equal number of priming conditions. Blocks were randomized individually for each participant and the order of blocks was varied following a Latin Square design.

\section{Materials}

The target words were identical to Experiment 1.

\section{Results}

The mean naming latencies and error rates are summarized in Table 2. Naming latencies faster than $300 \mathrm{~ms}$ or slower than $1000 \mathrm{~ms}$ were removed and counted as outliers $(0.5 \%$ of the data). An ANOVA was run with
Prime Type (begin-related, reversed begin-related, reversed first-syllable, or control) as the independent variable.

\section{Naming latencies}

The main effect of Prime Type was significant $\left(F_{1}(3,45)=9.61, M S_{\mathrm{e}}=54.70, p<.01 ; F_{2}(2,88)=15.37\right.$, $\left.M S_{\mathrm{e}}=140.53, p<.01\right)$. Naming latencies were fastest in the begin-related condition, followed by the reversed first-syllable condition, the control condition, and the reversed begin-related condition. The $12 \mathrm{~ms}$ difference between the begin-related and the reversed begin-related condition was highly significant $\left(t_{1}(15)=5.48, S D\right.$ $\left.=9.16, p<.001 ; t_{2}(44)=4.81, S D=17.90, p<.001\right)$. The reversed begin-related condition was not statistically different from the control condition $\left(t_{1}(15)<\right.$ $\left.1 ; t_{2}(44)<1\right)$ or from the reversed first-syllable $\left(t_{1}(15)=\right.$ $1.75, S D=5.80$, n.s.; $\left.t_{2}(44)<1\right)$.

\section{Error rates}

The overall error rate was $2.1 \%$. The errors were equally distributed across the conditions (see Table 2), and there were no significant effects in the error analysis.

\section{Discussion}

As in Experiment 1, begin-related primes yielded faster RTs compared to the control condition. This replicates the effect obtained in the first experiment with different participants. The significant difference between the begin-related and the reversed begin-related condition must be due to a masked onset priming effect and not a segmental overlap effect because the segmental match/mismatch of these two conditions is exactly the same. The fact that there is no segmental overlap effect in this experiment is further demonstrated by the lack of an advantage of the reversed first-syllable condition over the control or the reversed begin-related condition. Therefore, the outcome of Experiment 2 suggests that the segmental overlap hypothesis has to be modified. Pure segmental overlap independent of segmental position does not yield a priming effect. Apparently, segmental position is coded by the visual word recognition system as is, for instance, assumed by certain models of reading (e.g., Zorzi et al., 1998).

Table 2

Mean naming latencies (in milliseconds) and percentage errors (in parentheses) in Experiment 2

\begin{tabular}{lccc}
\hline Condition & Example & Mean RT & Mean priming effect (Control-Condition) \\
\hline Begin-related & $(\% \%$ balans\%\%-BANAAN) & $444(2.2)$ & $12(0.9)$ \\
Reversed begin-related & $(\% \% l$ ansba\%\%-BANAAN) & $457(2.6)$ & $-1(1.3)$ \\
Reversed first-syllable & $(\% \% \% \% \%$ ba\%\%-BANAAN) & $454(2.2)$ & $2(0.9)$ \\
Control & $(\% \% \% \% \% \% \% \%$-BANAAN) & $456(1.3)$ & \\
\hline
\end{tabular}


One may argue that the failure of any form-priming effect from reversed begin-related and the reversed firstsyllable condition may have to do with their lexical status. Whereas the begin-related prime balans is a word, both lansba and $b a$ are not. However, in Experiment 1 the non-word prime $b a$ yielded just as much priming as the word prime balans for the target BANAAN. Furthermore, Forster and Davis (1991) demonstrated that the onset effect could be obtained for non-word targets (e.g., fosk-FENT; Experiment 4) as well as for word targets combined with non-word primes (e.g., zuroZERO; Experiments 2+3). Therefore, the lexical status is unlikely to be the main source of the difference between balans on the one hand and lansba or $\% \% \% \% b a$ on the other hand. More likely, the position of the segments seems to be the crucial factor, as suggested in the previous paragraph.

Before I come to the General Discussion and a modification of the segmental overlap hypothesis, there is one further data point that is not predicted by a pure $\mathrm{SOH}$. The third and last experiment was designed to validate this data point for the Dutch language.

\section{Experiment 3: Word naming with simple-onset and complex-onset targets}

Words can start with a simple onset (e.g., C) or a complex onset (e.g., CC or CCC). Kinoshita (2000) observed that facilitation due to overlap of the initial letter only occurred when English target words started with a simple onset (e.g., penny-PASTE) but not when targets had a complex onset (e.g., bingo-BLISS). She argued that this result suggests that the sequential, leftto-right nature of the masked onset priming effect "is better interpreted in terms of a speech production process which takes the onset as a unit of articulatory planning" (Kinoshita, 2000). Kinoshita's claim is in contrast with a pure segmental overlap hypothesis, which does not predict that phonological units such as syllables or sub-syllabic units such as syllable onsets or rhymes should play a role for the magnitude of a formpriming effect. For the $\mathrm{SOH}$, solely the amount of segmental overlap between prime and target determines the magnitude of a form-priming effect (see Schiller, 1998, 2000). Therefore, the current experiment is an attempt to replicate Kinoshita's (2000) results in Dutch.

\section{Method}

\section{Participants}

Twenty-four participants from the same pool as described for Experiment 1 took part in the experiment.

\section{Procedure}

The procedure was identical to Experiment 1.

\section{Design}

There were two types of target words in this experiment: simple- and complex-onset words. Simple-onset words had a single consonant as the word onset (e.g., ballet 'ballet'); I will call them C-onset-words in the following. Complex-onset words had a consonant cluster as the word onset (e.g., broeder 'brother'), which will be called CC-onset-words. There was an equal number of each type of item in the experiment. Across the experiment, each target word was preceded by three different primes: a prime that matched the initial segment of the target word (e.g., b\%\%\%\%\%\%-BALLET or $\mathrm{b} \% \% \% \% \% \%$ - BROEDER), the first two segments of the target word (e.g., ba\%\%\%\%\% -BALLET or br\%\%\%\%\% BROEDER), or a control prime (e.g., \%\%\%\%\%\%\% LET or \%\%\%\%\%\%\%-BROEDER). The total of 216 trials (72 words $\times 3$ priming conditions) was divided into three blocks. The first block was preceded by 10 warm-up trials including different target words paired with control primes. In each block, there was an equal number of target word types and an equal number of priming conditions. Blocks were randomized individually for each participant and the order of blocks was varied following a Latin Square design.

\section{Materials}

Altogether, there were 72 bisyllabic Dutch words in this experiment. Half of the items were C-onset words with an average length in letters of 5.7 (range: 4-7 letters); the other half consisted of CC-onset words with an average length in letters of 6.9 (range: $5-8$ letters). All words corresponded to nouns and were of moderate frequency. Frequency was controlled between C-onset and CC-onset words. The mean frequency of occurrence per one million words (according to CELEX) was 22.87 for the C-onset words and 29.49 for the CC-onset words (see Appendix B for a complete list of items). The mean neighborhood density was 30.27 for the C-onset words and 12.34 for the CC-onset words. ${ }^{4}$

\section{Results}

The mean naming latencies and error rates are summarized in Table 3. Naming latencies faster than $300 \mathrm{~ms}$ or slower than $1000 \mathrm{~ms}$ were removed and counted as outliers $(0.1 \%$ of the data). An ANOVA was run with Prime Type (first-segment, first-two-segments, or

\footnotetext{
${ }^{4}$ Unfortunately, there was a relatively large difference in neighborhood density between C- and CC-onset words. However, given that even CC-words did not have particularly few neighbors, this actually increases the strength and speed of nonlexical naming responses and the size of a potential onset effect. Given the other constraining factors (phonological onset, frequency, etc.), it was not possible to completely match both types of targets.
} 
Table 3

Mean naming latencies (in milliseconds) and percentage errors (in parentheses) in Experiment 3

\begin{tabular}{|c|c|c|c|c|}
\hline Target Type & Condition & Example & Mean RT & $\begin{array}{l}\text { Mean priming effect } \\
\text { (Control-Condition) }\end{array}$ \\
\hline \multicolumn{5}{|c|}{ C-onset words } \\
\hline & First segment & (b\%\%\%\%\%\%\%-BALLET) & $485(1.2)$ & $5(0.3)$ \\
\hline & First two segments & (ba\%\%\%\%\%\%-BALLET) & $476(1.4)$ & $14(0.1)$ \\
\hline & Control & (\%\%\%\%\%\%\%-BALLET) & $490(1.5)$ & \\
\hline \multicolumn{5}{|c|}{ CC-onset words } \\
\hline & First segment & (b\%\%\%\%\%\%\%-BROEDER) & $495(1.3)$ & $5(0.3)$ \\
\hline & First two segments & (br\%\%\%\%\%\%-BROEDER) & $486(1.4)$ & $14(0.2)$ \\
\hline & Control & (\%\%\%\%\%\%\%\%-BROEDER) & $500(1.6)$ & \\
\hline
\end{tabular}

control) and Target Type (C-onset vs. CC-onset) as independent variables.

\section{Naming latencies}

The main effect of Target Type was significant $\left(F_{1}(1,23)=8.17, M S_{\mathrm{e}}=481.39, p<.01 ; F_{2}(1,70)=5.54\right.$, $\left.M S_{\mathrm{e}}=999.89, p<.05\right)$. C-onset words $(483 \mathrm{~ms})$ were produced faster than CC-onset words (494 ms). Also, the main effect of Prime Type was significant $\left(F_{1}(2,46)\right.$ $=32.19, M S_{\mathrm{e}}=76.55, p<.01 ; F_{2}(2,140)=37.90, M S_{\mathrm{e}}=$ $96.22, p<.01)$. Naming latencies were fastest in the first-two-segments condition $(481 \mathrm{~ms})$, followed by the first-segment condition $(490 \mathrm{~ms})$, and the control condition (495 ms). Most importantly, however, the interaction between Target Type and Prime Type was not significant $\left(F_{1}(1,23)<1 ; F_{2}(1,70)<1\right)$. This shows that the form-priming effect was no different in the CC-onset condition than in the $\mathrm{C}$-onset condition, i.e., there is no evidence from this experiment that the word onset as a unit played a role. While this is in contrast to what Kinoshita (2000) found, this was predicted by the segmental overlap hypothesis.

Bonferroni corrected $t$ tests (adjusted $\alpha=.025$ ) confirmed that the differences between the priming conditions were equally large for both target types. For the $\mathrm{C}$-onset and for CC-onset words, the $5 \mathrm{~ms}$ differences between the control and the first-segment condition were marginally significant $\left(t_{1}(23)=2.28, S D=11.40, p<\right.$ $.05 ; t_{2}(35)=2.29, S D=13.01, p<.05$ and $t_{1}(23)=2.26$, $S D=10.30, p<.05 ; t_{2}(35)=2.03, S D=13.95, p<.05$, respectively). The $9 \mathrm{~ms}$ difference between the first-segment condition and the first-two-segments condition was significant for the C-onset words $\left(t_{1}(23)=3.90, S D=\right.$ $\left.11.39, p<.005 ; t_{2}(35)=3.60, S D=14.00, p<.005\right)$ as was the $9 \mathrm{~ms}$ difference between the same conditions for the CC-onset words $\left(t_{1}(23)=3.95, S D=11.35, p<.005\right.$; $\left.t_{2}(35)=3.76, S D=14.89, p<.005\right)$.

\section{Error rates}

The overall error rate was only $1.4 \%$. Since the error rate was so low in this experiment and the errors were equally distributed across conditions, no formal analysis of the errors was conducted.

\section{Discussion}

This experiment showed that when the onset segment of the prime matches the onset segment of the target (both orthographically and phonologically), participants are faster to name the target words relative to a control condition. However, when prime and target match in the first two segments, naming latencies are even faster than in the first-segment priming condition. This is true for words with singleton onsets as well as for words with complex onsets in Dutch, in contrast to Kinoshita's (2000) results for English. The results of Experiment 3 suggest that the type of overlap in the internal syllabic structure between prime and target (simple vs. complex) does not affect masked priming of naming responses in Dutch, although Kinoshita (2000) did find such an effect in English; the reason for this discrepancy remains to be determined.

Interestingly, the facilitation effect for bisyllabic word targets seems to be quite stable across experiments and studies. Taking into account this experiment and the word-naming experiments reported in Schiller (1998), the priming effect amounts to between 5 and $10 \mathrm{~ms}$ per segment-independently of whether the segment is a consonant or a vowel. This latter result needs to be confirmed though by additional empirical data.

\section{General discussion}

Form-priming effects in word naming were investigated. Experiment 1 tested the effects of visually masked primes overlapping in the initial or final part with the target in a word-naming task. Effects of form relatedness were found under all conditions, except when there were mismatching initial segments in the prime, which blocked priming. The effect of mismatching segments makes a modification of the segmental overlap hypothesis necessary because in its original form the $\mathrm{SOH}$ was silent about the role of mismatching segments. Overall, initial overlap yielded stronger effects than final overlap. This position effect cannot be due to a segmental overlap effect-unless additional assumptions about the serial 
order of word form encoding are made (see below)_but could be due to a masked onset priming effect. Experiment 2 demonstrated that the segmental overlap hypothesis indeed needs further modification since the position of the segmental overlap seems to be crucial. When there was positional mismatch between the overlapping segments in prime and target, no priming effect occurred, contrary to what the original SOH predicted. Finally, I tested the influence of an additional factor of the target words on form-priming effects, namely onset complexity. In Experiment 3 , simple vs. complex onset targets were tested and no difference was found between these two target types in agreement with the segmental overlap hypothesis. This replicates earlier studies, which did not find a contingency of the priming effects on syllabic constituents (Schiller, 1998, 2000).

The outcome of the first two experiments clearly showed that mismatching segments decrease formpriming effects. Presumably, non-target segments from the prime activate non-target segments in the phonological output lexicon. These non-target segments might compete with the target segments for selection. Alternatively, as for example in the WEAVER model (Roelofs, 1997), the non-target segments activate non-target syllables when the target syllables are selected for speech production from a mental syllabary (Cholin, Schiller, \& Levelt, 2004; Cholin, Levelt, \& Schiller, submitted; Crompton, 1981; Levelt, 2001; Levelt, Roelofs, \& Meyer, 1999; Levelt \& Wheeldon, 1994). For instance, a first-syllable prime $b a$ would pre-activate the syllable /ba/ more than any other syllable in the syllabary (but other syllables including / $/$ / and /a/ will also receive some activation), while the second-syllable prime naan would most strongly pre-activate the syllable /nan/ (and also other syllables including $/ \mathrm{n} /$ and $/ \mathrm{a} /$ ). In a similar fashion, a begin-related prime like balans (for the target $B A N A A N$ ) would pre-activate, among others, the syllable /ba/, which corresponds to the first syllable of the target. In addition, all syllables including $/ 1 /, / \mathrm{n} /$, and $/ \mathrm{s} /$ would also become pre-activated to some extent. Similarly, the end-related prime propaan will strongly activate the second syllable /nan/ but also all syllables including $/ \mathrm{p} /, / \mathrm{r} /$, and $/ \mathrm{o} /$. However, on average, the syllable primes activate fewer non-target syllables in the syllabary than the word primes, and-in contrast to the word primes-no non-target segments become activated. In the WEAVER model, syllable selection is contingent on the Luce ratio: The more non-target syllables are activated, the lower the Luce ratio and the longer the selection times (Roelofs, 1997). Thus, a modified version of the segmental overlap hypothesis should state explicitly that form-priming effects become larger when the segmental overlap between prime and target is increased, but only if no mismatching segments are included. Otherwise, the facilitatory effect of matching segments can be minimized or canceled out by mismatching segments. When the segmental mismatch occurs at the onset, a strong interfering effect might be involved due to response competition.

I mentioned above that certain additional assumptions regarding the serial order of word form encoding would have to be made to account for the position effect found in Experiments 1 and 2 without making reference to a masked onset priming effect. Generally, no naming response might be given before the whole word is encoded (Wheeldon \& Lahiri, 1997). The second-syllable priming effects in the first experiment suggest this, for instance. However, sometimes articulation of the first segment(s) might start before the whole word has been encoded (see Kawamoto, Kello, Jones, \& Bame, 1998; Meyer, Roelofs, \& Levelt, 2003; Schriefers \& Teruel, 1999). This type of a "strategic" effect in speeded naming situations could be responsible for the position effect found in Experiment 1, i.e. the advantage of initial over final prime-target overlap. Such an "onset" effect might modulate the segmental overlap effect and could account for the observed pattern of results.

In summary, I have shown here that form-priming effects in word naming can be obtained with primes overlapping in the initial or final part with Dutch bisyllabic targets (Experiment 1). This result supports the segmental overlap hypothesis (Schiller, 1998, 2000) and also the response competition hypothesis (Forster \& Davis, 1991). However, mismatching segments clearly have a negative effect, presumably because the activation of non-target segments must be suppressed when the target word's segments/syllables are activated. Moreover, in the first experiment a position effect was found: Initial primes were more effective than final ones. This might be due to an "onset" effect as described in the previous paragraph that modulates the segmental overlap effect. The importance of the position of segmental overlap was further demonstrated in Experiment 2. Some positional coding clearly occurs because a reversed begin-related prime (e.g., lans $b a)$ did not yield any effect on the target word $B A N A A N$ in Experiment 2, despite extensive segmental overlap. Whether the positional coding scheme is absolute or relative (Grainger \& Whitney, 2004; Peressotti \& Grainger, 1995, 1999; Stevens \& Grainger, 2003) in the naming task cannot be decided on the basis of the current results and remains an open question for future research. Onset complexity did not have an effect in this study (Experiment 3), as predicted by the segmental overlap hypothesis.

\section{Modification of the segmental overlap hypothesis}

The original $\mathrm{SOH}$ has to be modified to account for the current results. A modified version of the $\mathrm{SOH}$ should predict the following: "The amount of 
facilitation due to form overlap between prime and target is contingent on the number of phonological segments that match/mismatch in particular positions between prime and target. Unless there is at least a relative positional match, no priming effect is predicted." Possibly, an "onset" effect due to incomplete encoding of the target-i.e., participants start to name the target before it is completely encoded-might occur, which yields an advantage of initial over final overlap.

This modified version of the segmental overlap hypothesis can account for the findings of the current study. Most importantly, when there are no mismatching segments between primes and targets (as e.g., in the syllabic primes in Experiment 1) there is more priming than in the case where there are mismatching segments (as e.g., in the whole-word primes). Furthermore, the advantage of initial over final overlap in the same experiments might either be due to a strategic onset effect applied in speeded naming tasks, namely starting to articulate before having encoded the target completely, possibly involving a response deadline (Lupker, Brown, \& Colombo, 1997; Meyer et al., 2003), or due to a masked onset priming effect.

Interestingly, Experiment 2 revealed a (relative) position effect, suggesting that positional coding effects known from visual word recognition also affect naming, even when the prime does not contain mismatching segments (i.e. the reversed second-syllable condition). This could possibly mean that segments in the prime code their (relative) position and use this coding to constrain the set of possible target responses. This touches upon the relation between perception and produc- tion (see Schiller \& Meyer, 2003), and constitutes an interesting issue for future research.

\section{Acknowledgments}

The research of Niels O. Schiller was supported by a fellowship from the Royal Netherlands Academy of Arts and Sciences (Koninklijke Nederlandse Akademie voor Wetenschappen; KNAW) and Grant No. 453-02-006 from the Netherlands Organisation for Scientific Research (Nederlandse Organisatie voor Wetenschappelijk Onderzoek; NWO). The experiments reported in this paper were carried out at the Max Planck Institute for Psycholinguistics in Nijmegen, The Netherlands. Parts of the data were presented at the XIIth conference of the European Society for Cognitive Psychology (September 2001), at the Third International Conference on the Mental Lexicon (October 2002), and at the 6th symposium for psycholinguistics in Barcelona (March 2003). Thanks go to Ardi Roelofs and Jo Ziegler for helpful discussion and Rob Hartsuiker for his comments on an earlier draft of the manuscript. The author thanks Frouke Hermens, Marcel van Gerven, Suzan Kroezen, Janneke van Elferen, and Anne Jacobs for setting up and running the experiments, and Arie van der Lugt (Otto-van-Guericke University Magdeburg) and James McQueen (Max Planck Institute for Psycholinguistics, Nijmegen) for providing scripts to compute particular lexical characteristics of the target words. Finally, the author would like to thank Glen Bodner and two anonymous reviewers for their helpful comments and suggestions on earlier versions of the manuscript.

\section{Appendix A. Stimulus materials from Experiments 1 and 2}

\begin{tabular}{lll}
\hline Targets & & \multicolumn{1}{c}{ Primes } \\
\cline { 2 - 3 } & \multicolumn{1}{c}{ Begin-related } & \multicolumn{1}{c}{ End-related } \\
\hline anker ('anchor') & angel ('angle') & bunker ('bunker') \\
auto ('car') & aula ('hall') & veto ('veto') \\
banaan ('banana') & balans ('balance') & propaan ('propane') \\
beha ('bra') & beroep ('profession') & geisha ('geisha') \\
beitel ('chisel') & beiaard ('carillon') & titel ('title') \\
beker ('cup') & berin ('female bear') & kweker ('breeder') \\
bezem ('broom') & boezem ('bosom') & bever ('beaver') \\
borstel ('brush') & bordeel ('brothel') & voorstel ('suggestion') \\
cactus ('cactus') & cacao ('cacao') & prospectus ('brochure') \\
cirkel ('circle') & circus ('circus') & snorkel ('snorkel') \\
citroen ('lemon') & citer ('zither') & festijn ('celebration') \\
dolfijn ('dolphin') & dollar ('dollar') & rubriek ('category') \\
fabriek ('factory') & fazant ('pheasant') & toto ('pools') \\
foto ('photograph') & fobie ('phobia') & verkeer ('traffic') \\
geweer ('rifle') & getal ('figure') & altaar ('altar') \\
gitaar ('guitar') & giraf ('giraffe') & filter ('filter') \\
halter ('weights') & halma ('halma') &
\end{tabular}




\begin{tabular}{|c|c|c|}
\hline \multirow[t]{2}{*}{ Targets } & \multicolumn{2}{|c|}{ Primes } \\
\hline & Begin-related & End-related \\
\hline hamer ('hammer') & haven ('harbor') & kamer ('room') \\
\hline kameel ('camel') & kampong ('kampong') & formeel ('formal') \\
\hline kanon ('cannon') & kajuit ('cabin') & xenon ('xenon') \\
\hline ketel ('kettle') & kever ('beetle') & zetel ('seat') \\
\hline konijn ('rabbit') & koren ('grain') & tonijn ('tuna') \\
\hline kubus ('cube') & kuras ('cuirass') & rebus ('rebus') \\
\hline magneet ('magnet') & magma ('magma') & planeet ('planet') \\
\hline masker ('mask') & massief ('solid') & cracker ('cracker') \\
\hline mijter ('mitre') & mijl ('mile') & slijter ('wine dealer') \\
\hline molen ('wind mill') & modem ('modem') & kolen ('coal') \\
\hline motor ('motor bike') & model ('model') & rotor ('rotor') \\
\hline penseel ('brush’) & pendule ('pendulum') & universeel ('universal') \\
\hline pinguin ('penguin') & pincet ('tweezers') & fortuin ('fortune') \\
\hline pleister ('plaster') & pleidooi ('plea') & breister ('knitter') \\
\hline raket ('rocket') & ravijn ('ravine') & etiket ('label') \\
\hline ratel ('rattle') & radar ('radar') & spatel ('spatula') \\
\hline robot ('robot') & robijn ('ruby') & fagot ('bassoon') \\
\hline sigaar ('cigar') & signaal ('signal') & haar ('hair') \\
\hline sleutel ('key') & sleur ('inefficiency') & gereutel ('rattle') \\
\hline spijker ('nail') & spijs ('food') & kijker ('spectator') \\
\hline stempel ('stamp') & stemming ('mood') & drempel ('threshold') \\
\hline tafel ('desk') & tapijt ('carpet') & rafel ('frayed end') \\
\hline tijger ('tiger') & tijding ('message') & krijger ('warrior') \\
\hline tractor ('tractor') & trachee ('trachea') & refractor ('refractor') \\
\hline trompet ('trumpet') & trommel ('drum') & pipet ('pipette') \\
\hline varken ('pig') & varia ('miscellanea') & merken ('notice') \\
\hline vlinder ('butterfly') & vliering ('attic') & cilinder ('cylinder') \\
\hline wortel ('carrot') & wording ('genesis') & mortel ('mortar') \\
\hline
\end{tabular}

\section{Appendix B. Stimulus materials from Experiment 3}

\begin{tabular}{llll}
\hline & \multicolumn{2}{c}{ Target onset type } & \multicolumn{1}{c}{ Complex (CC-onset-words) } \\
\hline \multicolumn{1}{c}{ Simple (C-onset-words) } & \multicolumn{1}{c}{ smeris ('cop') } \\
\hline ballet ('ballet') & hamer ('hammer') & briljant ('juwel') & smokkel ('smuggling') \\
banaan ('banana') & magneet ('magnet') & broeder ('brother') & snavel ('beak') \\
beha ('bra') & masker ('mask') & drempel ('threshold') & speeksel ('saliva') \\
beitel ('chisel') & mijter ('mitre') & druppel ('drop') & spiegel ('mirror') \\
beker ('cup') & molen ('mill') & framboos ('rasberry') & spijker ('nail') \\
bezem ('broom') & motor ('motor bike') & grendel ('bolt') & stapel ('pile') \\
borstel ('brush') & penseel ('brush') & groente ('vegetables') & station ('station') \\
divan ('divan') & pincet ('tweezers') & klavier ('piano') & steiger ('scaffolding') \\
dolfijn ('dolphin') & pinguin ('pinguin') & kliniek ('clinic') & stekker ('plug') \\
fabriek ('factory') & raket ('rocket') & klooster ('monastery') & stempel ('stamp') \\
fazant ('pheasant') & ratel ('rattle') & knevel ('gag') & stilte ('silence') \\
festijn ('feast') & robot ('robot') & knikker ('marble') & stoppel ('stubble') \\
foto ('photograph') & tafel ('table') & krediet ('credit') & stuiver ('five cent coin') \\
gevel ('gable) & tapijt ('carpet') & kritiek ('criticism') & trede ('rung') \\
geweer ('rifle') & tijger ('tiger') & kruimel ('crumb') & twijfel ('doubt') \\
giraf ('giraffe') & varken ('pig') & kwartier ('quarter') & vrede ('peace') \\
gitaar ('guitar') & vogel ('bird') & plafond ('ceiling') & zwobleem ('problem') \\
halter ('dumbbell') & wortel ('carrot') & &
\end{tabular}




\section{References}

Baayen, R. H., Piepenbrock, R., \& Gulikers, L. (1995). The CELEX lexical database (CD-ROM). Philadelphia: Linguistic Data Consortium, University of Pennsylvania.

Bodner, G. E., \& Masson, M. E. J. (1997). Masked repetition priming of words and nonwords: Evidence for a nonlexical basis for priming. Journal of Memory and Language, 37, 268-293.

Bodner, G. E., \& Masson, M. E. J. (2001). Prime validity affects masked reprtition priming: Evidence for an episodic resource account of priming. Journal of Memory and Language, 45, 616-647.

Cholin, J., Schiller, N. O., \& Levelt, W. J. M. (2004). The preparation of syllables in speech production. Journal of Memory and Language, 50, 47-61.

Cholin, J., Levelt, W. J. M., \& Schiller, N. O. (submitted). Effects of syllable frequency in speech production.

Coltheart, M., Curtis, B., Atkins, P., \& Haller, M. (1993). Models of reading aloud: Dual-route and parallel-distributed-processing approaches. Psychological Review, 100, 589-608.

Coltheart, M., \& Rastle, K. (1994). Serial processing in reading aloud: Evidence for dual-route models of reading. Journal of Experimental Psychology: Human Perception and Performance, 20, 1197-1211.

Coltheart, M., Rastle, K., Perry, C., Langdon, R., \& Ziegler, J. (2001). DRC: A dual route cascaded model of visual word recognition and reading aloud. Psychological Review, 108, 204-256.

Coltheart, M., Woollams, A., Kinoshita, S., \& Perry, C. (1999). A position-sensitive Stroop effect: Further evidence for a left-to-right component in print-to-speech conversion. Psychonomic Bulletin \& Review, 6, 456-463.

Cortese, M. J. (1998). Revisiting serial position effects in reading. Journal of Memory and Language, 39, 652-665.

Crompton, A. (1981). Syllables and segments in speech production. Linguistics, 19, 663-716.

Dell, G. S., \& Reich, P. A. (1981). Stages in sentence production: An analysis of speech error data. Journal of Verbal Learning and Verbal Behavior, 20, 611-629.

Forster, K. I. (1998). The pros and cons of masked priming. Journal of Psycholinguistic Research, 27, 203-233.

Forster, K. I., \& Davis, C. (1991). The density constraint on form-priming in the naming task: Interference effects from a masked prime. Journal of Memory and Language, 30, 1-25.

Forster, K. I., Mohan, K., \& Hector, J. (2003). The mechanics of masked priming. The state of the art. In S. Kinoshita \& S. J. Lupker (Eds.), Masked priming (pp. 3-37). Hove: Psychology Press.

Grainger, J., \& Ferrand, L. (1996). Masked orthographic and phonological priming in visual word recognition and naming: Cross-task comparisons. Journal of Memory and Language, 35, 623-647.

Grainger, J., \& Whitney, C. (2004). Does the huamn mnid raed wrods as a wlohe? Trends in Cognitive Sciences, 8, 58-59.

Job, R., \& Peressotti, F. (2001). Serial effects in pseudoword reading. Abstracts of the Psychonomic Society, 6, 75.

Kawamoto, A. H., Kello, C. T., Jones, R. M., \& Bame, K. A. (1998). Initial phoneme versus whole word criterion to initiate pronunciation: Evidence based on response latency and initial phoneme duration. Journal of Experimental Psychology: Learning, Memory, and Cognition, 24, 862-885.

Kinoshita, S. (2000). The left-to-right nature of the masked onset effect in naming. Psychonomic Bulletin \& Review, 7 , 133-141.

Kinoshita, S. (2003). The nature of masked onset priming effects in naming: A review. The state of the art. In S. Kinoshita \& S. J. Lupker (Eds.), Masked priming (pp. 223238). Hove: Psychology Press.

Kinoshita, S., \& Woollams, A. (2002). The masked onset priming effect in naming: Computation of phonology or speech-planning. Memory \& Cognition, 30, 237-245.

Levelt, W. J. M. (2001). Spoken word production: A theory of lexical access. Proceedings of the National Academy of Sciences, 98, 13464-13471.

Levelt, W. J. M., Roelofs, A., \& Meyer, A. S. (1999). A theory of lexical access in speech production. Behavioral and Brain Sciences, 22, 1-75.

Levelt, W. J. M., \& Wheeldon, L. (1994). Do speakers have access to a mental syllabary? Cognition, 50, 239-269.

Lupker, S. J., Brown, P., \& Colombo, L. (1997). Strategic control in a naming task: Changing routes or changing deadlines? Journal of Experimental Psychology: Learning, Memory, and Cognition, 23, 570-590.

Meyer, A. S., Roelofs, A., \& Levelt, W. J. M. (2003). Word length effects in picture naming: The role of a response criterion. Journal of Memory and Language, 48, 131-147.

Montant, M., \& Ziegler, J. C. (2001). Can orthographic rimes facilitate naming? Psychonomic Bulletin \& Review, 8, 351356.

Newman, R. S., Sawush, J. R., \& Luce, P. A. (1997). Lexical neighborhood effects in phonetic processing. Journal of Experimental Psychology: Human Perception and Performance, 23, 873-889.

O'Seaghdha, P. G., \& Marin, J. W. (2000). Phonological competition and cooperation in from-related priming: sequential and nonsequential processes in word production. Journal of Experimental Psychology: Human Perception and Performance, 26, 57-73.

Peressotti, F., \& Grainger, J. (1995). Letter-position coding in random constant arrays. Perception \& Psychophysics, 57, 875-890.

Peressotti, F., \& Grainger, J. (1999). The role of letter identity and letter position in orthographic priming. Perception \& Psychophysics, 61, 691-706.

Plaut, D. C., McClelland, J. C., Seidenberg, M. S., \& Patterson, K. (1996). Understanding normal and impaired word reading: Computational principles in quasi-regular domains. Psychological Review, 103, 56-115.

Rastle, K., \& Coltheart, M. (1999). Serial and strategic effects in reading aloud. Journal of Experimental Psychology: Human Perception and Performance, 25, 482-503.

Roelofs, A. (1997). The WEAVER model of word-form encoding in speech production. Cognition, 64, 249-284.

Schiller, N. O. (1998). The effect of visually masked syllable primes on the naming latencies of words and pictures. Journal of Memory and Language, 39, 484-507.

Schiller, N. O. (2000). Single word production in English: The role of subsyllabic units during phonological encoding. Journal of Experimental Psychology: Learning, Memory, and Cognition, 26, 512-528. 
Schiller, N. O., Costa, A., \& Colomé, A. (2002). Phonological encoding of single words: In search of the lost syllable. In C. Gussenhoven \& N. Warner (Eds.), Papers in laboratory phonology (Vol. 7, pp. 35-59). Berlin: Mouton de Gruyter.

Schiller, N. O., \& Meyer, A. S. (2003). Phonetics and phonology in language comprehension and production. Differences and similarities. Berlin: Mouton de Gruyter.

Schriefers, H., \& Teruel, E. (1999). Phonological facilitation in the production of two-word utterances. The European Journal of Cognitive Psychology, 11, 17-50.

Stevens, M., \& Grainger, J. (2003). Letter visibility and the viewing position effect in visual word recognition. Perception \& Psychophysics, 65, 133-151.

Treiman, R. (1985). Onsets and rimes as units of spoken syllables: Evidence from children. Journal of Experimental Child Psychology, 39, 161-181.
Treiman, R. (1986). The division between onsets and rimes in English syllables. Journal of Memory and Language, 25, 476-491.

Treiman, R., Fowler, C. A., Gross, J., Berch, D., \& Weatherston, S. (1995). Syllable structure or word structure? Evidence for onset and rime units with disyllabic and trisyllabic stimuli. Journal of Memory and Language, 34, 132-155.

Treiman, R., \& Zukowski, A. (1996). Children's sensitivity to syllables, onsets, rimes, and phonemes. Journal of Experimental Child Psychology, 61, 193-215.

Wheeldon, L. R., \& Lahiri, A. (1997). Prosodic units in speech production. Journal of Memory and Language, 37, 356-381.

Zorzi, M., Houghton, G., \& Butterworth, B. (1998). Two routes or one in reading aloud?: A connectionist dual-route model. Journal of Experimental Psychology: Human Perception and Performance, 24, 1131-1161. 